\title{
FLUXO DE FLUIDO ATRAVÉS DE UM MEIO POROSO FRACTAL DESORDENADO: ANÁLISE DAS TENSÕES DE CISALHAMENTO E EFEITOS DE ESCALA NA ESTIMATIVA DE FORÇAS VISCOSAS
}

\author{
I. A. BARBOSA ${ }^{1,2^{*}}$, A. BARROCA NETO ${ }^{1}$, S. F. B. JÁCOME ${ }^{1}$, L. R. DA SILVA ${ }^{1}$ E L. S. LUCENA ${ }^{1}$ \\ 'Universidade Federal do Rio Grande do Norte - UFRN \\ ${ }^{2}$ Instituto Federal do Rio Grande do Norte - IFRN \\ iderval.alves@ifrn.edu.br
}

Artigo submetido em novembro/2014 e aceito em junho/2015

DOI: $10.15628 /$ holos.2015.2611

\begin{abstract}
RESUMO
Investigamos alguns aspectos do fluxo bidimensional de um fluido viscoso newtoniano, através de um meio poroso desordenado, modelado por um sistema fractal aleatório, semelhante ao Tapete de Sierpinski. Este fractal é formado por obstáculos de diversos tamanhos, cuja função de distribuição segue uma lei de potência. Além do mais, estão aleatoriamente dispostos em um canal retangular. O campo de velocidades e outros detalhes da dinâmica dos fluidos são obtidos resolvendo-se, numericamente, as equações de Navier-
\end{abstract}

Stokes e as da continuidade, em nível de poros. Os resultados das simulações numéricas permitiram-nos fazer uma análise da distribuição das tensões de cisalhamento desenvolvidas nas interfaces sólido-fluido, e encontrar relações algébricas entre as forças viscosas ou de atrito e parâmetros geométricos do modelo. Com base nos resultados numéricos, propusemos relações de escala que envolvem os parâmetros relevantes do fenômeno, quantificando as frações dessas forças com relação às classes de tamanhos dos obstáculos.

PALAVRAS-CHAVE: Meios Porosos Desordenados, Leis de Potência, Geometria Fractal, Dimensão Fractal de Fracionamento e Sistemas Complexos Desordenados.

\section{FLUID FLOW THROUGH A DISORDERED POROUS MEDIA FRACTAL. ANALYSIS OF SHEAR STRESS AND EFFECT OF SCALE ON ESTIMATES OF VISCOUS FORCES}

\begin{abstract}
We have investigated some aspects of the twodimensional flow of a viscous Newtonian fluid through a disordered porous media modeled by a random fractal system similar to the Sierpinski carpet. This fractal is formed by obstacles of various sizes, whose distribution function follows a power law. They are randomly disposed in a rectangular channel. The velocity field and other details of fluid dynamics are obtained by solving numerically of the Navier-Stokes and continuity
\end{abstract}

equations at the pore level. The results of numerical simulations allowed us to analyze the distribution of shear stresses developed in the solid-fluid interfaces, and find algebraic relations between the viscous forces or of friction with the geometric parameters of the model. Based on the numerical results, we proposed scaling relations involving the relevant parameters of the phenomenon, allowing quantifying the fractions of these forces with respect to size classes of obstacles.

KEYWORDS: Disordered Porous Media, Power Laws, Fractal Geometry, Fractal Dimension Fractionation, Disordered Complex Systems. 


\section{INTRODUÇÃO}

O fluxo de um fluido viscoso, através de um meio poroso, é um fenômeno relevante em muitos campos da ciência e da tecnologia. Apresenta muitas aplicações práticas na indústria de petróleo, medicina, engenharia química e biologia (Dullien, 1979; Sahimi, 1995). Representa verdadeiro desafio para os pesquisadores que estudam fenômenos, tais como a exploração e a recuperação de petróleo (Aziz, 1979). Nos últimos anos, recebeu muita atenção dos físicos interessados em investigar os processos de transporte de fluidos em sistemas desordenados ou aleatórios, por exemplo (Andrade, 1995; Andrade, 1997; Macedo, 2001). Os pesquisadores usaram modelos baseados em aglomerados de percolação e redes complexas, dentre outros. No entanto, um problema muito interessante está relacionado à investigação do comportamento do fluxo de fluido quando o meio é fractal. Ou seja, uma análise de como a fractalidade do meio pode afetar as propriedades dinâmicas do sistema sólido-fluido. Neste trabalho, pretendemos examinar com detalhes essa investigação. Em alguns trabalhos anteriores, já se analisaram comportamentos relacionados a este tema (Barroca Neto, 2012). Entretanto, um dos efeitos importantes da dinâmica dos fluidos, envolvida nesses sistemas, está relacionado às forças desenvolvidas nas interações mecânicas entre o fluido e as partes sólidas que compõem o meio poroso e nele imersas. Ou seja, o fluido que escoa entre os obstáculos que compõem o meio origina uma força resultante denominada ação. Como decorrência, esses obstáculos produzem uma reação sobre a massa fluida, retardando-Ihe o seu fluxo. Esta força pode ser decomposta em duas componentes: uma força de arrasto, na direção do fluxo e responsável pela resistência ao avanço do fluido, e outra força de sustentação, normal à direção do fluxo. A força de arrasto, ou resistência ao avanço, é uma propriedade macroscópica do sistema, cuja sua medida está relacionada à resistência do fluxo do fluido, a qual surge naturalmente, quando um fluido é forçado a passar através de um meio poroso. Mais precisamente, a força de arrasto é composta de duas forças: a de pressão dinâmica e a de tensão de cisalhamento. A de pressão dinâmica é provocada pelas tensões normais, enquanto que a de tensão de cisalhamento é provocada pelas tensões tangenciais, que agem sobre as superfícies de elementos infinitesimais de áreas. Dessa forma, temos duas forças básicas: arrasto de pressão (ou de forma) e arrasto de atrito de superfície (ou viscoso). Quando o fluxo de um fluido ocorre lentamente, caracterizado como escoamento a baixa velocidade, as forças viscosas tendem a prevalecer sobre as de pressão e, como decorrência, o fluxo habitualmente é denominado Stokeano ou com baixo número de Reynolds (Çengel \& Cimbala, 2007; Fox, 2006). No caso de escoamento à baixa velocidade, a medida do arrasto viscoso, por exemplo, torna-se de grande interesse na indústria de petróleo. Isto se deve ao fato desta estar associada às forças desenvolvidas nas formações rochosas dos reservatórios de petróleo. Por conseguinte, diretamente relacionada à quantidade de energia de pressão requerida para que ocorra o fluxo do fluido em seu interior. De um modo geral, em fluxos bidimensionais, a resultante da força viscosa também terá componente horizontal e vertical. Entretanto, para fluxos de fluidos que escoam predominantemente em uma direção, digamos horizontal, espera-se que a componente horizontal tenda a ser muito superior à componente vertical. Normalmente, para o fluxo de um fluido, incompressível e Newtoniano, escoando em estado estacionário, a força de arrasto atuando na direção $x, F_{a, x}$, causada pelas tensões normais e de cisalhamento que agem nas superfícies sólidas, é dada pela equação (Çengel \& Cimbala, 2007; Fox, 2006). 


$$
F_{a, x}=\int_{A}(p \cos \theta) d A+\int_{A}(\tau \operatorname{sen} \theta) d A
$$

sendo, $\theta$ o ângulo formado pela normal ao elemento de superfície $d A$ com a direção do escoamento, $x, p$ a pressão e $\tau$, a tensão de cisalhamento. Na equação (1), a primeira integral corresponde à força de arrasto de forma, enquanto a segunda integral corresponde à força de arrasto viscoso ou de atrito, na direção $x$. Esta última é a propriedade de interesse nesta pesquisa.

Em inúmeros fenômenos físicos é comum deparar-se com o escoamento de um fluido em torno de um objeto sólido, por exemplo, o escoamento em torno de um cilindro. Neste caso, dizemos que o escoamento é exterior. Tradicionalmente, esses tipos de escoamentos são estudados de uma maneira teórica e/ou experimental. Porém, devido a grandes avanços na área do cálculo numérico e das tecnologias de computação, tem-se desenvolvido métodos numéricos computacionais altamente robustos e eficazes, cada vez mais confiáveis e que estão disponibilizados em pacotes comerciais, que se propõem a resolver numericamente as equações que governam a dinâmica dos fluidos envolvida no problema. Ou seja, avanços em métodos numéricos, mais especificamente, em dinâmica de fluidos computacional ou computational fluid dynamics (CFD), permitem realizar simulações de fluxos de fluido, sob condições de contorno complexas apropriadas, que expressam, por exemplo, a geometria fractal. Isto torna possível analisar, em detalhes, o fluxo de fluidos em meios porosos, diretamente no espaço de poros, determinando os campos de velocidade, de pressão e de temperatura e, ainda mais, com base nestes resultados predizer propriedades de interesse. Alguns estudos têm considerado a presença de obstáculos do mesmo tamanho, distribuídos aleatoriamente em um canal regular (Moraes, 2009; Andrade, 2005). Outros consideraram o empacotamento de Apolônio para os obstáculos (Rafael et al., 2001). Nosso trabalho tem como objetivo analisar a distribuição das tensões viscosas e quantificar a força de arrasto viscoso do sistema, possibilitando o desenvolvimento de relações algébricas, v. g. lei de potência, com base em resultados de simulações numéricas e propriedades geométricas construtivas do modelo que simplifica o meio poroso. Além disso, analisar e quantificar as frações dessa força com relação às classes de tamanhos dos obstáculos. Esse é o foco principal da pesquisa realizada neste trabalho, ou seja, analise e quantificação do efeito de escala em modelos com geometria fractal na medida das forças viscosas desenvolvidas nas superfícies dos obstáculos sólidos que compõem o meio poroso.

Ademais, na natureza, o petróleo é encontrado distribuído no meio poroso, localizado nos poros das rochas (Dullien, 1979). A heterogeneidade, em várias escalas, das propriedades das rochas, que formam o reservatório, exerce um enorme impacto sobre a forma como o fluxo de fluidos ocorre no seu interior (King et al., 2001). Isto afeta todos os aspectos físicos do fluxo, definindo quanto de petróleo pode ser extraído ou recuperado. O fluxo ocorre na escala de poros que, bem como os grãos, são irregulares, de tamanhos variados e de geometria complexa, dando origem a uma grande incerteza sobre a distribuição espacial das heterogeneidades existentes. Assim, o reservatório de petróleo apresenta características de um meio poroso desordenado, em nível de espaço de poros, afetando diretamente suas propriedades dinâmicas. Com o objetivo de estudar esta variabilidade neste trabalho, o meio poroso, por simplificação, sem perda de generalidade, foi representado por modelo em que a heterogeneidade foi conseguida através da construção de modelo geométrico fractal. 
Levando em conta um meio contínuo, vamos considerar um fluido viscoso incompressível e Newtoniano, escoando sob condições estacionárias e isotérmicas. As expressões matemáticas necessárias para descrever, em detalhes, a dinâmica dos fluidos no interstício de poros são dadas pelas equações de continuidade e de Navier-Stokes, que se reduzem a (Çengel \& Cimbala, 2007; Fox, 2006)

$$
\begin{gathered}
\nabla \cdot \vec{v}=0 \\
\rho \vec{v} \cdot \nabla \vec{v}=-\nabla p+\mu \nabla^{2} \vec{v}
\end{gathered}
$$

onde $\nabla$ é o operador vetorial $\frac{\partial}{\partial x} \vec{i}+\frac{\partial}{\partial y} \vec{j}+\frac{\partial}{\partial z} \vec{k}$, e $\rho$ e $\mu$ são a densidade e a viscosidade dinâmica do fluido; $\vec{v}$ e p são os campos de velocidade e de pressão, respectivamente. Estas equações podem ser resolvidas numericamente, utilizando técnicas de CFD. Usamos o software FLUENT (2012), que utiliza a técnica de diferenças finitas, baseada em volume de controle [16], para resolver as equações governantes da dinâmica de fluidos viscosos, como definidas pelas Equações (2) e (3). A região de fluxo, espaço de poros, foi discretizada em uma malha de pontos, usando o software GAMBIT (Gambit, 2014), viabilizando a realização de simulações de fluxos de fluidos viscosos em meios porosos simplificados por modelos geométricos fractais construídos usando o software MATLAB (Gilat, 2006).

\section{METODOLOGIA}

\subsection{GEOMETRIA DO MEIO POROSO}

Neste trabalho, a geometria, que representa o meio poroso, consiste de um canal retangular bidimensional de dimensões: $L T=5,25 m$ e $h=2,0 m$. É um tubo curto, de altura $h=2,0 m$, formado por três regiões, ou seja, uma caixa centralizada de comprimento $L c=3,0 m$, onde é ligado zonas auxiliar anterior e posterior, de comprimentos $L b a=0,75 m$ e $L b p=1,5 m$, respectivamente, na direção do fluxo. Ver figura 1. Nesta caixa são alocados aleatoriamente os obstáculos (discos). As zonas auxiliares são necessárias para minimizar os efeitos sobre o campo de fluxo nos terminais do tubo. As condições de contorno de não escorregamento são aplicadas ao longo de todas as interfaces do tipo sólido-fluido. Na entrada do tubo foi adotada uma velocidade prescrita constante $V_{0}=0,001 \mathrm{~m} / \mathrm{s}$ na direção normal, enquanto que, na saída, foi imposta uma pressão prescrita $p=0$. O fluido escolhido foi um óleo de densidade $\rho=960 \mathrm{~kg} / \mathrm{m}^{3}$ e de viscosidade dinâmica $\mu=0,048 \mathrm{~kg} /(\mathrm{m} \cdot \mathrm{s})$. Finalmente, as faces superiores e inferiores do tubo foram consideradas como sendo paredes sólidas. Para caracterizar o regime de escoamento no interior do tubo, o número de Reynolds $R=\frac{\rho v d}{\mu}$ foi calculado na entrada do tubo para um comprimento característico do escoamento $d$, correspondente à altura $h$ do tubo e velocidade característica $v$, igual à velocidade na entrada no tubo $v_{0}$ para todas as amostras analisadas nesta pesquisa. Logo $R=\frac{960 \times 0,001 \times 2,0}{0,048}=40$ (Bear, 1988). Portanto, na entrada do tubo, o regime de escoamento pode ser considerado laminar, ou seja, não turbulento. Espera-se 
que o amortecimento do fluxo causado pelos obstáculos suavize o movimento do fluido, reduzindo ainda mais esse valor no interior da amostra porosa.

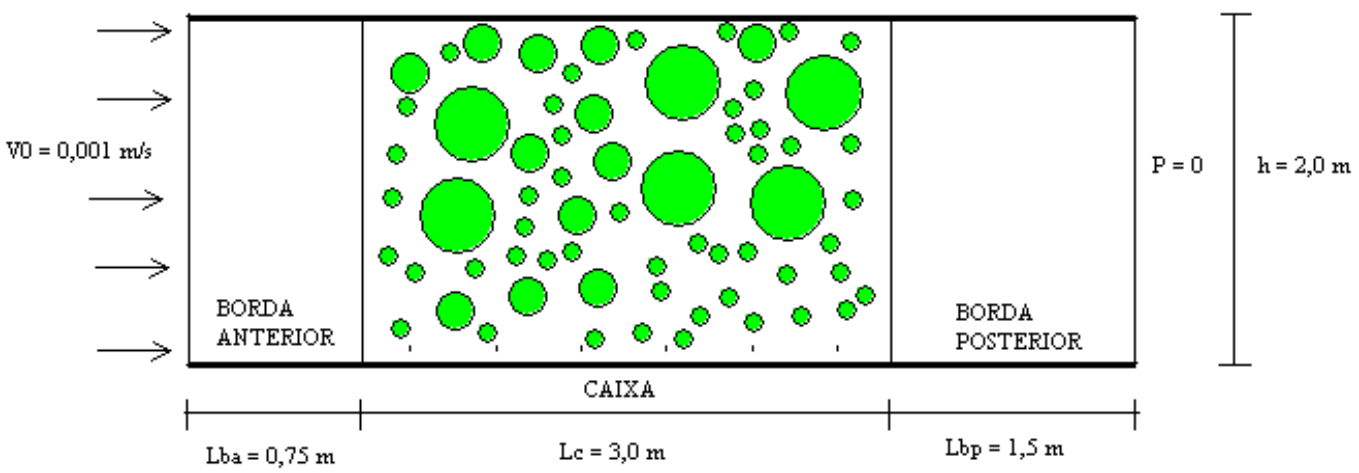

Figura 1: Foto ilustrativa do tubo curto composto pelas bordas anterior e posterior e a caixa onde se encontram os obstáculos.

\subsection{MODELAGEM DO MEIO POROSO}

Para a modelagem do meio poroso, foi construída uma série de 15 conjuntos de amostras, cada uma com quatro gerações. Estas gerações correspondem à geometria fractal do modelo, usada nas simulações em CFD e realizadas neste trabalho. Este modelo pertence a uma classe denominada Meios Porosos Desordenados (MPD), cuja construção tomou como base o Tapete de Sierpinski (TS) (Mandelbrot \& Benoit, 2006). Matematicamente, os TS são fractais determinísticos, isto é, são conjuntos auto-semelhantes exatos que podem ser gerados pelo método Sistema de Funções Iterativas (IFS) em que a fractalidade é conseguida no limite de infinitas iterações de transformações afins que envolvem contração e translação, aplicadas a um conjunto inicial, particularmente, no nosso caso, um quadrado (Fisher, 1995). Por conseguinte, podemos utilizar o método de remoção de peças para conduzir o processo iterativo na a construção do Tapete de Sierpinski (TS). O processo segue os seguintes passos: (a) começamos a partir de uma superfície delimitada por um quadrado cheio; (b) dividimos o quadrado cheio em nove quadrados congruentes; (c) removemos o quadrado central; (d) repetimos as duas últimas etapas ad infitum, com os quadrados preenchidos restantes. Este é um procedimento relativamente simples em que, no limite de infinitas iterações, obtém-se o fractal desejado. A figura 2 mostra mais claramente este processo. Portanto, o tapete TS é a base para a construção do modelo da classe MPD que foi analisado nesta pesquisa. Neste trabalho, propusemos uma pequena variação na cosntrução dos tapetes TS. Estes deram origem aos Tapetes de Sierpinski Modificados (TSM), que consequentemente determinam a classe de modelos MPD. Portanto, a modelagem consiste em uma sequência de amostras obtidas através de um processo iterativo análogo ao utilizado na construção do tapete Sierpinski. Cada modelo é constituído de obstáculos sólidos, representados sob a forma de discos que estão dispersos aleatoriamente no espaço (caixa). A quantidade e os tamanhos dos discos são obtidos usando como base a estrutura fractal de tapetes, tipo o de Sierpinski e seguem uma distribuição em lei de potência, cujo expoente é definido como a dimensão fractal do modelo geométrico. Neste caso, considerou-se os diâmetros dos discos no tapete TSM como sendo iguais aos lados dos quadrados vazios do tapete TS. A figura 3 mostra mais claramente este procedimento.

$\mathrm{Na}$ criação dos tapetes de Sierpinski (TS), temos inicialmente uma caixa quadrada de tamanho $L=3,0 \mathrm{~m}$. É dividida em 9 partes, correspondendo a um fator de redução de escala 
$a=3$. Na primeira iteração, é obtida a estrutura do tapete correspondente ao seu primeiro nível de geração. Os quadrados cheios são pretos e os vazios (removidos) são brancos. Veja a figura 2. Neste nível, é possível identificar os três parâmetros $a$, fator redução de escala; $b$, o número de quadrados cheios (não removidos), e $c$, o número de quadrados removidos. Caracterizam o tapete Sierpinski (TS) e, consequentemente, cada modelo da classe MPD. Estes três parâmetros estão assim relacionados: $a^{2}=b+c$. No presente caso, ou seja, no nível 1 , assumem os seguintes valores: $a=3, b=8$ e $c=1$.

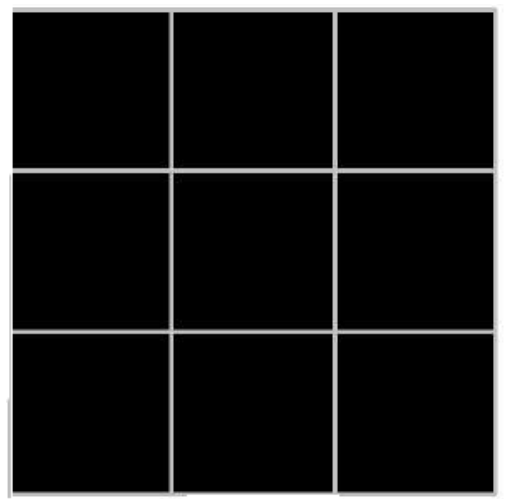

Nível 0

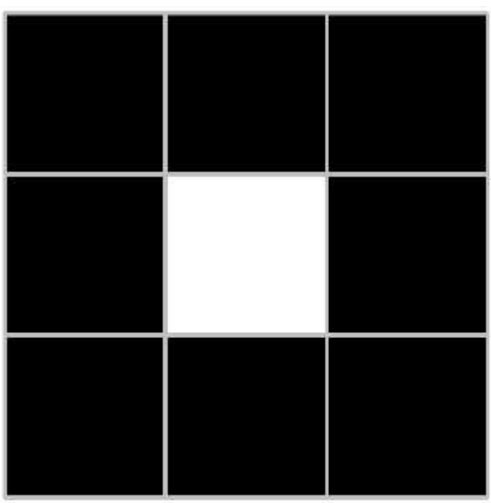

Nível 1

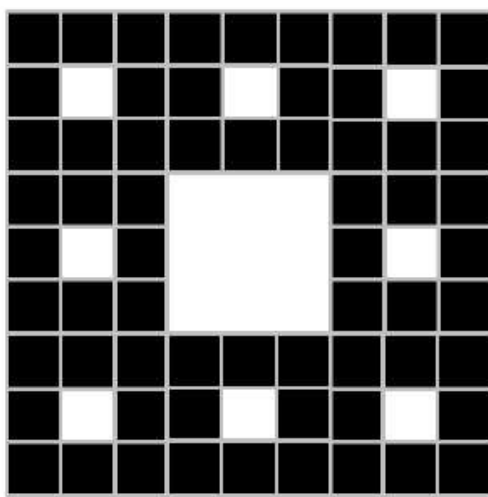

Nível 2

Figura 2: Foto ilustrativa do processo de criação dos tapetes de Sierpinski (TS).

Na construção do Tapete de Sierpinski modificado, que passamos a identificar por TSM, destacamos os seus três primeiros níveis, que passamos a denominar gerações. Nestes tapetes, os quadrados cheios são azuis e os espaços (quadrados) vazios são brancos, que serão substituídos por discos, na cor preta, com diâmetros iguais ao comprimento do lado do respectivo quadrado. A figura 3 mostra o TSM correspondente ao modelo MPD.

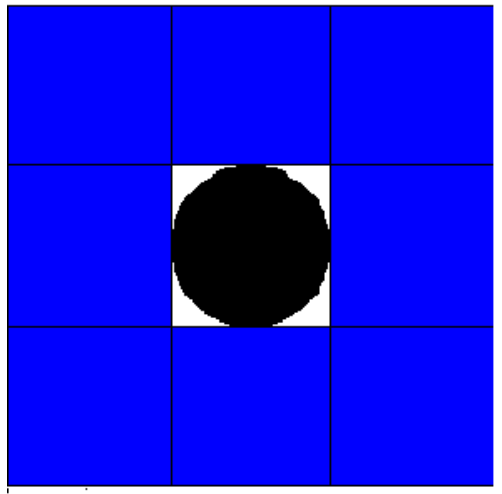

Nível 1

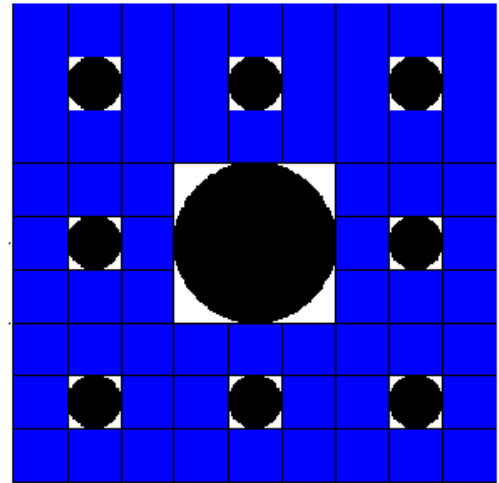

Nível 2

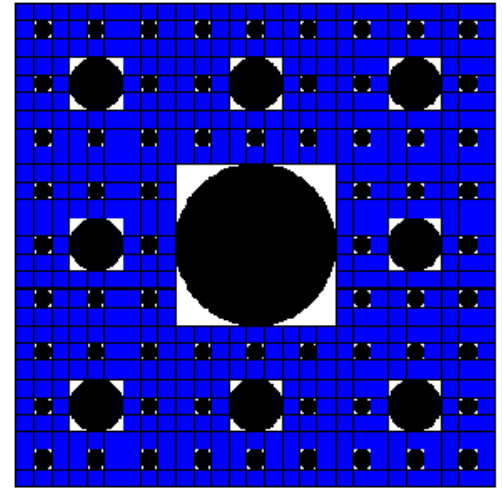

Nível 3

Figura 3: Foto ilustrativa do processo de criação dos tapetes de Sierpinski modificados (TSM).

O processo de criação de discos para os modelos MPD está ilustrado na figura 4, para a segunda, terceira e quarta gerações; correspondentes ao modelo considerado neste trabalho. Mais precisamente, para cada iteração, constrói-se um tapete, que gera várias amostras porosas, correspondentes ao modelo MPD associado a ele, nesse nível de geração, $g$. Esta amostra é composta por $N_{g}$ obstáculos, fragmentados em classes de ordem $q$. Isto quer dizer que, na geração $g$, temos $N_{g}$ discos, assim distribuídas: $N_{g}=$ quantidade de discos de raio $1+$ quantidade de discos de raio $2+\ldots+$ quantidade de discos de raio $q$. Desta forma, $R_{q}$ corresponde ao tamanho (raio) dos discos da classe $q$, mensurados pelo respectivo raio. Por 
outro lado, $n_{g, q}$ corresponde a função que determina o número de discos de uma determinada classe de tamanhos $q$, para um determinado nível de geração $g$.

No topo da figura 4 temos o segundo, terceiro e quarto níveis do tapete (TSM). Na parte inferior da mesma figura temos a formação da sequência sucessiva de gerações de amostras porosas correspondente ao modelo MPD, cujos discos são distribuídos sequencial e aleatoriamente na caixa com dimensões $h \times L c$. Os discos são pretos.

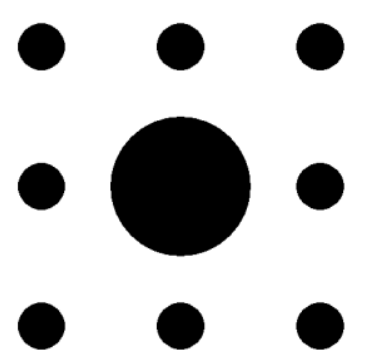

Nível 2

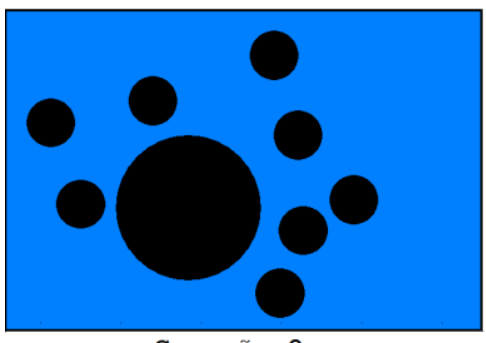

Geração 2

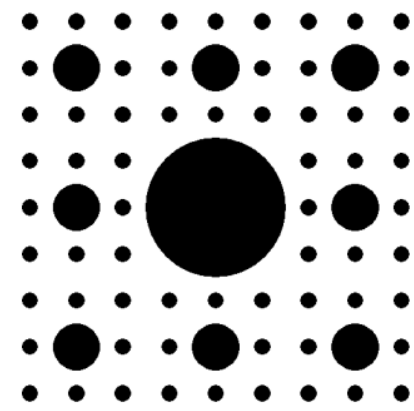

Nível 3

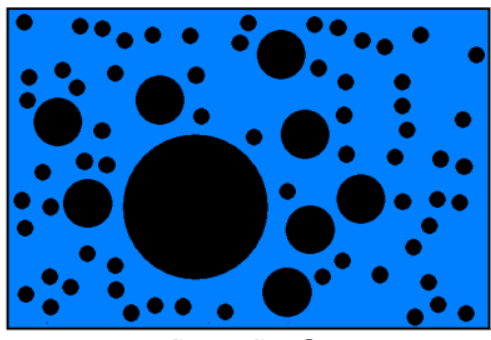

Geração 3

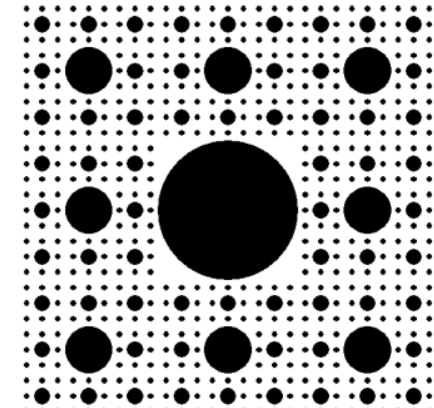

Nível 4

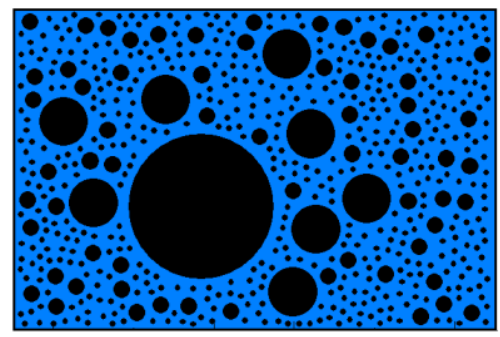

Geração 4

Figura 4: Foto ilustrativa do processo de criação de discos do Modelo MPD, com base no tapete de Sierpinski modificado (TSM).

A Tabela 1, de dupla entrada, exibida logo abaixo, ilustra mais claramente este procedimento. Assim, para cada nível de geração $g$, temos um conjunto de amostras porosas do tipo MPD , em que são realizadas as simulações em CFD. Na última linha temos o total de discos $N_{g}$ para cada geração " $g$ " e, na última coluna, têm-se os tamanhos (raios) dos discos, $R_{q}$, para cada classe $q$.

Tabela 1: Esta tabela representa a função de distribuição fractal dos tamanhos de discos $n_{g, q}$ do modelo MPD.

\begin{tabular}{|c|c|c|c|c|c|}
\hline Classe $q$ & 1 & 2 & 3 & 4 & $R_{q}(\mathrm{~cm})$ \\
\hline 1 & 1 & 1 & 1 & 1 & 30,9019 \\
\hline 2 & 0 & 8 & 8 & 8 & 10,3006 \\
\hline 3 & 0 & 0 & 64 & 64 & 3,4335 \\
\hline 4 & 0 & 0 & 0 & 512 & 1,1445 \\
\hline$N_{g}$ & 1 & 9 & 73 & 585 & \\
\hline
\end{tabular}




\subsection{EXPRESSÕES MATEMÁTICAS PARA OS MODELOS MPD}

Apresentamos, a seguir, as equações correspondentes aos modelos MPD. A regra para a determinação do número de discos de mesmo tamanho, como uma função da classe $q$ para um determinado nível de geração $g$, segue uma lei exponencial geral de base $b$, dada por

$$
n_{g, q}=c \cdot b^{q-1}
$$

assim, o número total de discos na geração $g$ pode ser dado por

$$
N_{g}=\sum_{i=1}^{g} c \cdot b^{i-1}
$$

e para a sequência de raios correspondentes às classes $q$ tem-se um decaimento exponencial geral de base $a$, que é dado por

$$
R_{q}=\frac{R_{1}}{a^{(q-1)}}
$$

em que $R_{1}$ é o raio do disco de maior tamanho, correspondente à classe $q=1$. Por outro lado, $a, b$ e $c$ são os parâmetros que caracterizam o modelo MPD, tal como previamente definido.

Por conseguinte, uma relação entre estas duas funções exponenciais, dadas pelas equações (4), para $n_{g, q}$, e (6), para $R_{q}$, pode ser obtida, já que elas dependem apenas da variável $q$, para uma determinada geração $g$. Como decorrência, o gráfico $\ln \left(n_{g, q}\right) \times \ln \left(R_{q}\right)$, que pode ser visto na figura 7 (a), é uma reta. Neste caso, as duas variáveis, digamos $n_{g, q}$ e $R_{q}$, variam segundo uma lei de potência, em que o expoente é igual à dimensão fractal $D_{f f}$, ou dimensão fractal de fracionamento, do sistema. Por conseguinte,

$$
n_{g, q} \sim R_{q}^{-D_{f f}} \Leftrightarrow c \cdot b^{q-1} \sim\left(\frac{R_{1}}{a^{(q-1)}}\right)^{-D_{f f}}
$$

Podemos escrever a equação da dimensão fractal $D_{f f}$ como uma função, apenas, dos parâmetros geométricos do modelo. Para tanto, basta tomar o limite da relação para $q$ tendendo ao infinito. Desta forma, isolando $D_{f f}$, obtemos

$$
D_{f f}=\frac{\ln b}{\ln a}
$$

por conseguinte, para o modelo analisado, MPD, a dimensão fractal tem valor $D_{f f}=1,8928$. Que é igual ao valor da dimensão fractal do Tapete de Sierpinski (TS). Ainda, a equação (7) pode ser escrita da seguinte forma

$$
n_{g, q}=C_{R} R_{q}^{-D_{f f}}
$$

em que $C_{R}$ é a constante de proporcionalidade decorrente da equação (7). O seu valor pode ser obtido dessa equação para qualquer valor de $q$, ou seja,

$$
C_{R}=c \cdot b^{q-1}\left(\frac{a^{(q-1)}}{R_{1}}\right)^{-D_{f}}=661,0418
$$

com $R_{1}$ dado em $\mathrm{cm}$. Os demais parâmetros já foram definidos anteriormente. $O$ valor de $C_{R}$, poderia ter sido tirado do gráfico $\ln \left(n_{g, q}\right) \times \ln \left(R_{q}\right)$, mostrado na figura 7 (a). Logo, obtemos para a equação (9A), anterior, o resultado que segue 


$$
n_{g, q}=661,04187 R_{q}^{-1,8928}
$$

esta é a uma lei de potência que caracteriza a função de distribuição fractal de tamanhos dos obstáculos para os modelos MPD, analisados nesta pesquisa.

\section{RESULTADOS E DISCUSSÕES}

A figura 5 mostra um padrão particular de fluxo, resultante das simulações em CFD, realizadas nesta pesquisa, relacionadas à primeira, segunda, terceira e quarta gerações para 0 terceiro conjunto de amostras porosas correspondentes aos modelos MPD, respectivamente. Esta figura mostra como o padrão de fluxo mensurado pelo campo de velocidades, varia com o avanço das gerações.
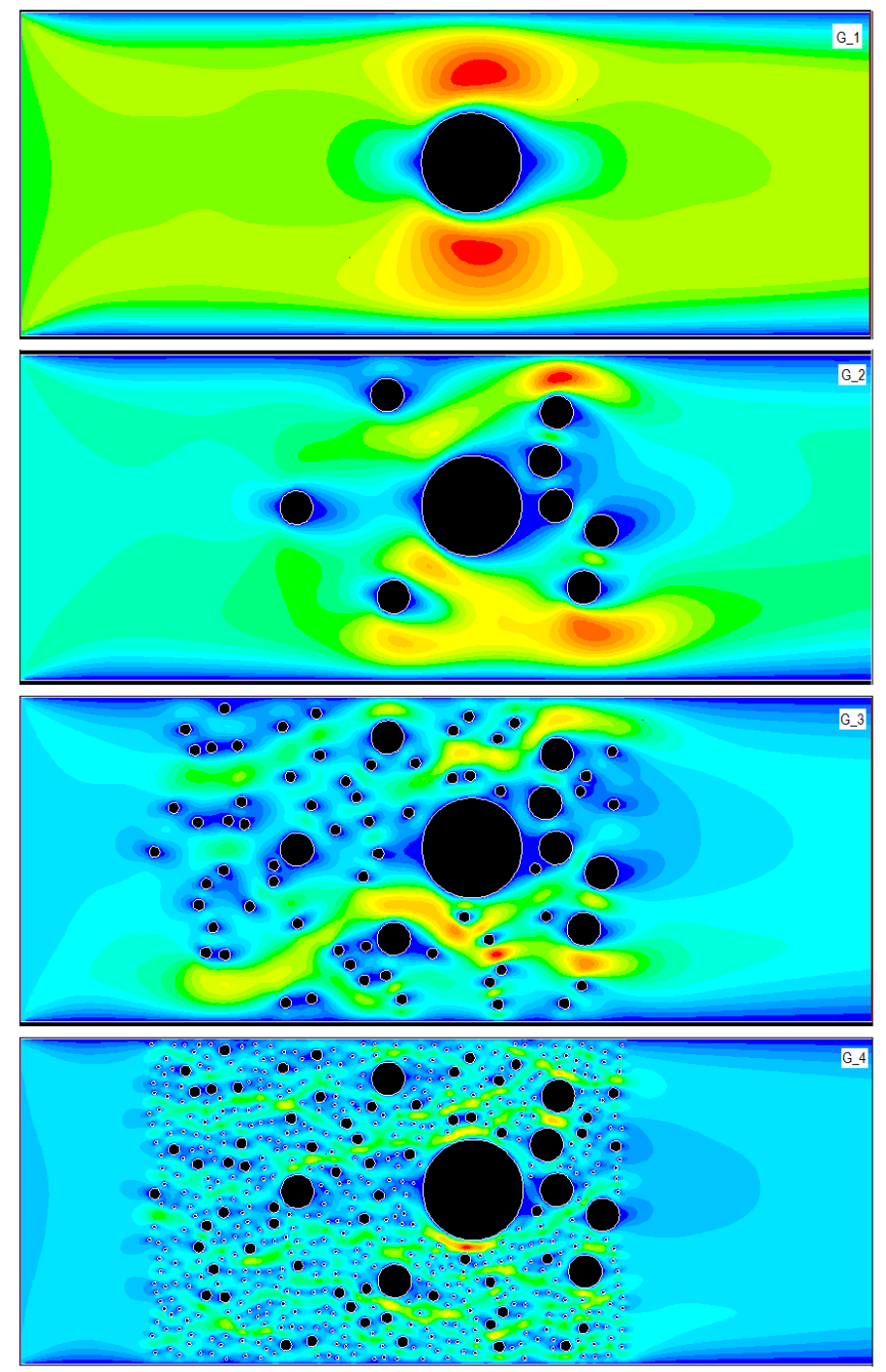

Figura 5: Contorno da magnitude das velocidades para a primeira $\left(G_{-1}\right)$, segunda $\left(G_{-2}\right)$, terceira $\left(G_{-3}\right)$ e quarta ( $G_{-4}$ ) gerações do modelo MPD.

Este fenômeno ocorre devido ao fato de haver uma diminuição na medida da porosidade e um aumento na medida da superfície específica dos obstáculos, devido à adição de novos discos, cada vez menores. Por outro lado, com o avanço das gerações, o tamanho do espaço poroso diminui, tornando-se mais difícil para o fluido escoar através do meio poroso. Além do 
que, é possível identificar diferentes canais preferenciais, pois através deles o fluido escoa entre os obstáculos. A presença desses canais fica cada vez mais proeminente ao longo das gerações. Devido à presença de vários discos menores, canais maiores são substituídos por outros menores, com menor intensidade de fluxo. Pode-se ver que a estrututura de fluxo passa gradualmente de fluxo espacialmente localizado para deslocalizado (Stanley \& Andrade Jr., 2001). Esta ocorrência na estrutura de fluxo, distribuição do fluxo de velocidades, altera a configuração das distribuições das tensões de cisalhamento desenvolvidas nas superfícies sólidas dos obstáculos que compõem o meio poroso. Ou seja, o mesmo obstáculo apresenta variação na distribuição das tensões de cisalhamento em suas superfícies, quando se passa de uma geração para a outra. De maneira bem clara, vemos isto através da figura 5 , em que as velocidades mais elevadas são representadas pela cor vermelha, e as menos, pela azul. Os discos são pretos. 0 fluxo ocorre da esquerda para a direita, direção de escoamento, $x$.
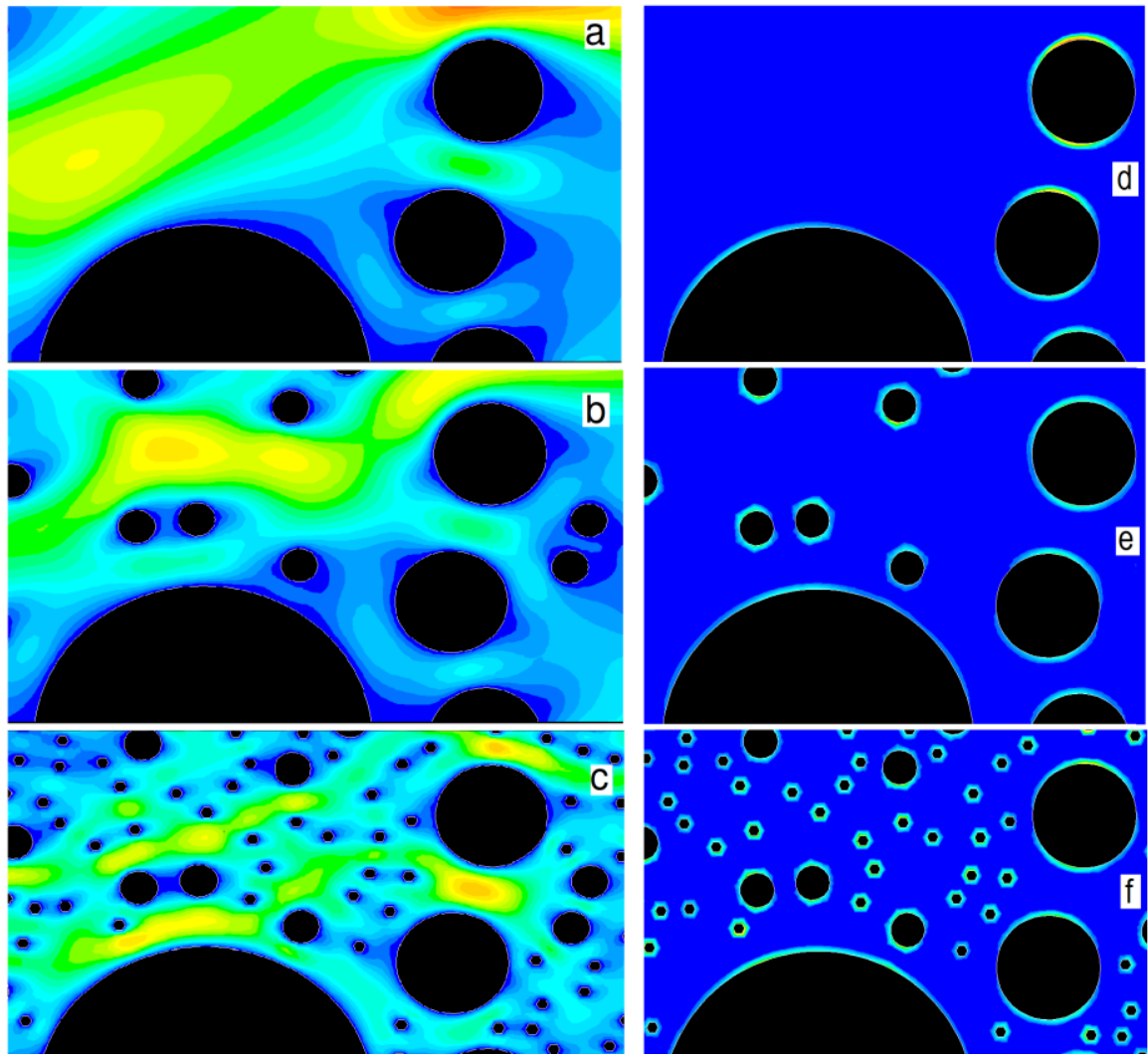

Figura 6: Detalhe ampliado do contorno de magnitude das velocidades para (a) segunda, (b) terceira e(c)quarta gerações do modelo MPD. Também é exibido o contorno de magnitude das tensões de cisalhamento na direção $x$, para as correspondentes gerações em (d), (e) e (f).

Segundo as obras consultadas, em escoamentos exteriores, os maiores gradientes de velocidades ocorrem em uma zona denominada camada limite, próxima às superfícies dos obstáculos (Çengel \& Cimbala, 2007; Fox, 2006). É nesta fina camada que praticamente se desenvolvem as tensões de cisalhamento, devido às propriedades viscosas, efeitos de atrito, do fluido. Observando a figura 6 , podemos ter uma noção da forma dessa camada, apresentando a tenue configuração das distribuições das tensões de cisalhamento que se desenvolvem nas superfícies dos obstáculos. Nesta figura, podemos observar com mais detalhe, como o padrão de fluxo altera a distribuição das tensões de cisalhamento analisadas nesta pesquisa. Apresenta-se também, na mesma figura, detalhe ampliado do contorno de magnitude das velocidades para (a) segunda, (b) terceira e (c) quarta gerações do modelo MPD. Adicionalmente, exibe-se o contorno 
de magnitude das tensões de cisalhamento na direção $x$, para as correspondentes gerações em (d), (e) e (f), onde se destacam detalhes, na mesma região anterior, sobre o contorno das tensões de cisalhamento. As de menor intensidade (praticamente nulas) estão em azul. É possível identificar, nesta figura, as variações nas distribuições das tensões de cisalhamento que se desenvolvem na fina camada limite para um determinado obstáculo.

Dado o sistema constituído pelo meio poroso MPD, denominamos $F_{a q}$ a força média que atua na classe de obstáculos de tamanhos $R_{q}$. Ou seja, em cada classe de ordem $q$, com $n_{g, q}$ discos de tamanhos $R_{q}$, atua uma força média $F_{a q}$. Na verdade, os obstáculos, quando simulados em CFD, são prismas regulares com bases inscritas em círculos de raios $R_{q}$. Por simplificação, vamos considerar que são cilindros de profundidade unitária com base circular de raio $R_{q}$. Dessa forma, a força de cisalhamento $F_{a q}$, que atua na superfície lateral dos cilindros de uma determinada classe $q$, é dada por

$$
F_{a q}=2 \pi \tau_{q} \frac{R_{q}}{100} n_{g, q}=\frac{1}{50} \pi \tau_{q} R_{q} n_{g, q}
$$

para $F_{a q}$ dada em $\mathrm{N}$, e $R_{q}$ dado em $\mathrm{cm}$, e as tensões de cisalhamento $\tau_{q}$ dadas em $\mathrm{N} / \mathrm{m}^{2}$.

A figura 7 mostra: (a) distribuição dos tamanhos dos obstáculos, gráfico $\ln n_{g, q} \times \ln R_{q}$; (b) leis de potência entre a força de cisalhamento média $F_{a q}$, de cada classe $q$, e os tamanhos dos obstáculos $R_{q}$, gráficos $\ln F_{a q} \times \ln R_{q}$, para as gerações $G_{2}, G_{3}$ e $G_{4}$, respectivamente. Em cada gráfico, os círculos vermelhos correspondem aos dados obtidos das simulações numéricas e as retas em azul, o ajuste pelo Método dos Mínimos Quadrados.
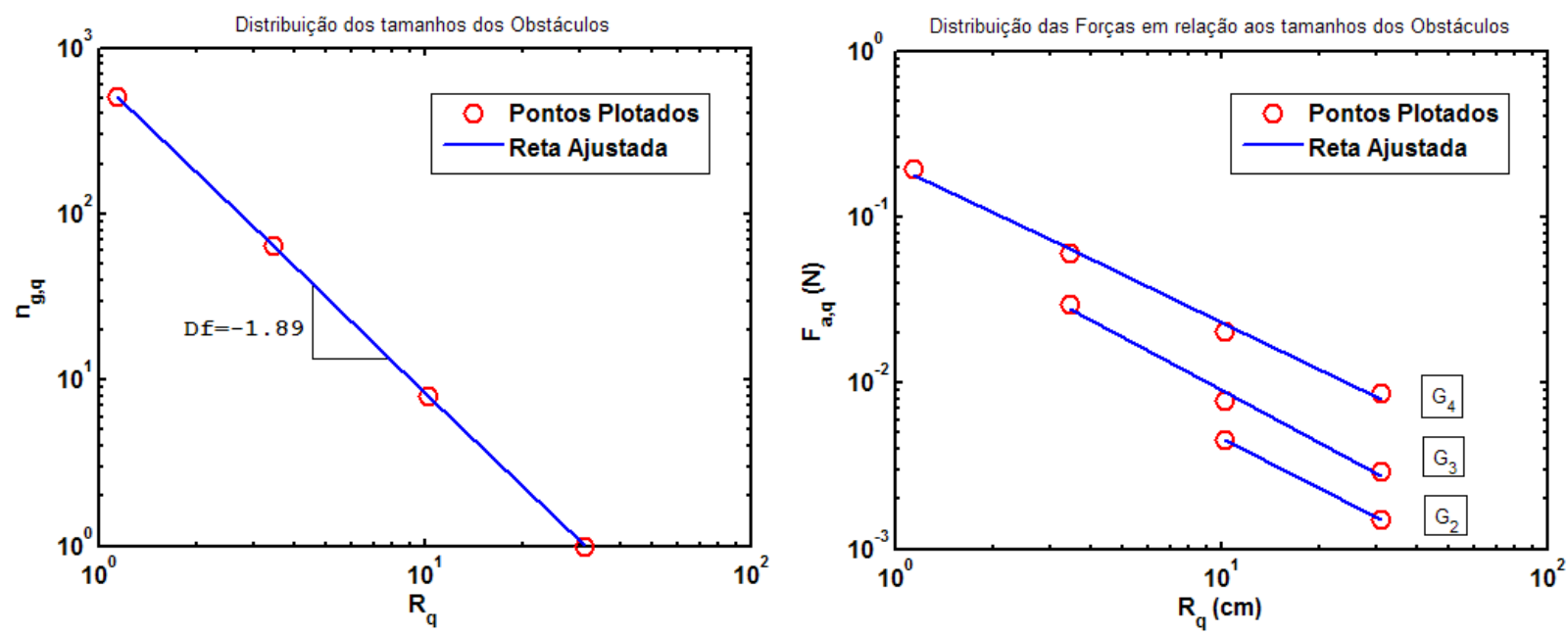

Figura 7: (a) Distribuição dos tamanhos dos obstáculos, gráfico $\ln n_{g, q} \times \ln R_{q}$; (b) leis de potência entre a força de cisalhamento média de cada classe " $q$ " e os tamanhos dos obstáculos $R_{q}$, gráficos $\ln F_{a q} \times \ln R_{q}$, para as gerações $G_{2}$, e $G_{4}$ respectivamente.

Dos resultados advindos das simulações em CFD, observou-se que as tensões de cisalhamento $\tau$, obtidas como valores numéricos médios encontrados nas 15 amostras analisadas, não variam muito de uma classe para outra, dentro de uma determinada geração, correspondente a uma amostra porosa. As figuras 8 e 9 mostram a distribuição dos valores das 
tensões de cisalhamento e seu correspondente histograma para todos os discos da classe de tamanhos $q=4$ para geração $g=4$, nas direções $x$ e $y$, respectivamente. É possível observar que boa parte dos valores concentra-se na região central delimitada pelas duas linhas azuis e que o histograma dos dados aponta para uma distribuição Gaussiana. Isto nos garante que a média é uma medida representativa dos valores encontrados para os $\tau_{q x}$ e $\tau_{q y}$, respectivamente.
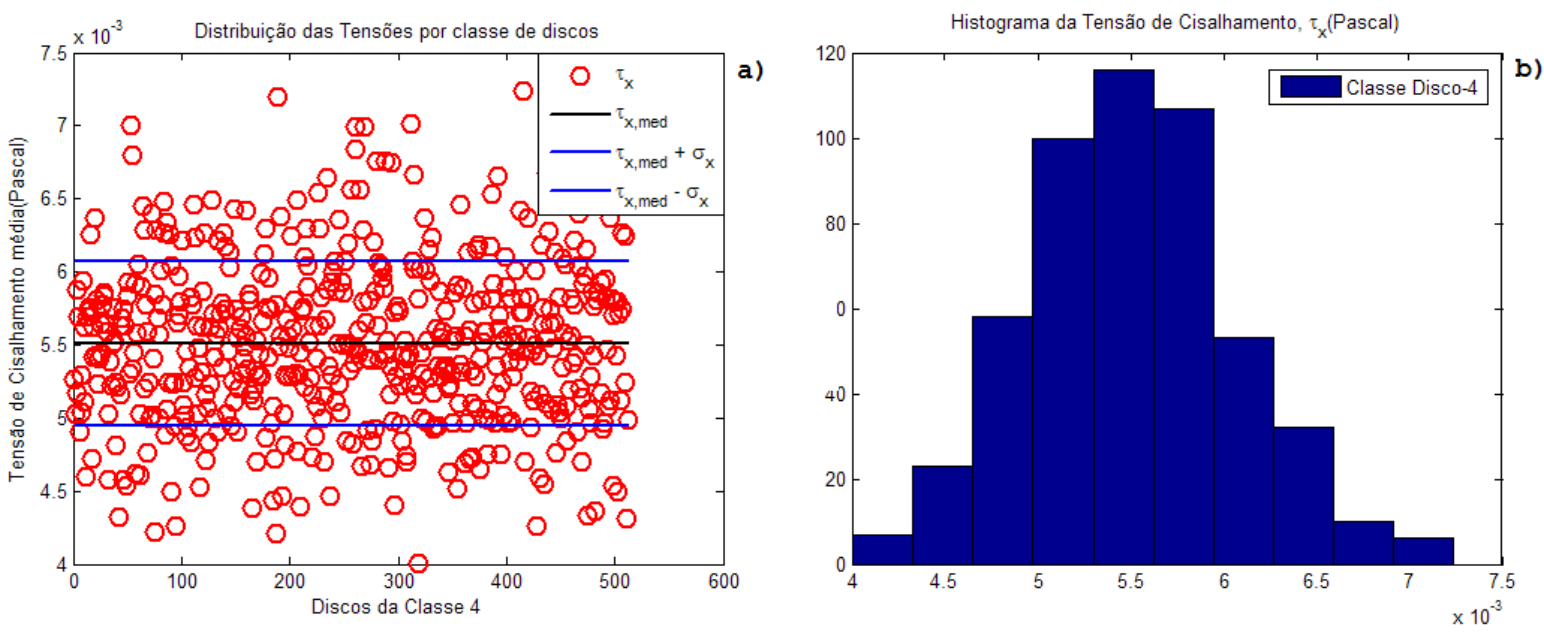

Figura 8: A figura mostra: (a) Distribuição das tensões de cisalhamento médias na direção $X$, com relação às classes de tamanhos, $q=4$, para a geração de ordem, $g=4$, gráfico $\left(\tau_{q X} \times q\right)$; (b) seu respectivo histograma.
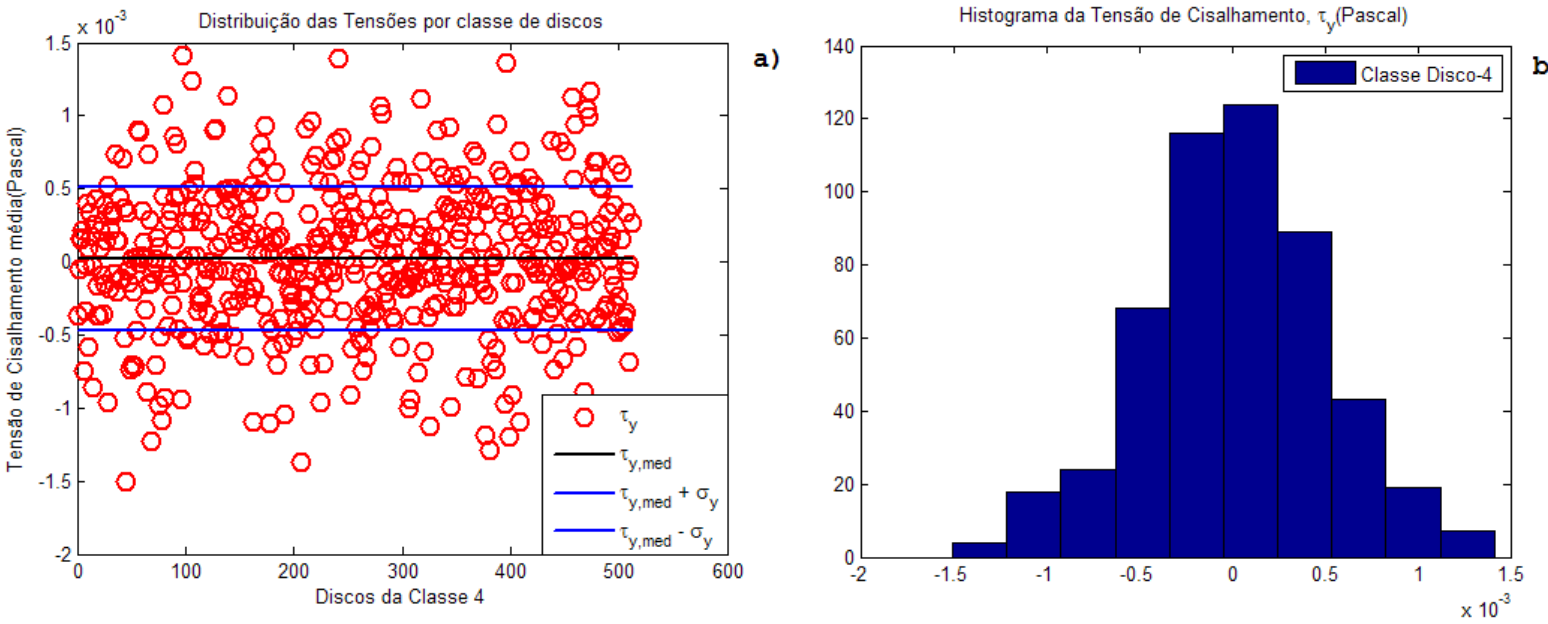

Figura 9: (a) Distribuição das tensões de cisalhamento médias na direção $y$, com relação às classes de tamanhos, $q=4$, para a geração de ordem, $g=4$, gráfico $\left(\tau_{q y} \times q\right)$; (b) seu respectivo Histograma.

Em virtude dos resultados das simulações, vistos anteriormente, em CFD, observou-se que, para uma mesma geração correspondente a uma amostra porosa, as tensões de cisalhamentos $\tau$ não variam muito dentro de uma classe. Com base nas figuras (8) e (9), observa-se que o valor relevante é a tensão de cisalhamento média $\tau_{q x}$, na direção $x$, pois o valor médio na direção $y$ é tecnicamente nulo, ou seja, $\tau_{q y}=0$. Portanto, neste trabalho foi feita a análise apenas na direção $x$, isto é, estudou-se apenas $\tau_{q x}$. Por conseguinte, a partir das equações $(9 A)$ e (10), obtemos 


$$
F_{a q}=C_{F} R_{q}^{\left(1-D_{f f}\right)} \text {, onde } C_{F}=\frac{1}{50} \pi \tau_{q x} C_{R}
$$

os valores médios obtidos nas simulações em CFD para as tensões de cisalhamento atuantes nas classes de tamanhos $q$, para cada geração $g$, que correspondem a uma amostra porosa, estão listados na Tabela 2, na página 18, adiante. Neste trabalho foram construídas duas abordagens para a análise do fenômeno envolvido. Particularmente, a simplificada e a aproximada. Primeiro, na abordagem simplificada, foi construído o equacionamento simplificado para o comportamento das forças viscosas $F_{a q}$. Consideraram-se apenas os valores médios de $\tau_{q x}$ para cada geração $g$, já que eles variam muito pouco dentro de cada uma dessas classes (ver tabela 2). Logo, o valor da constante $C_{F}$, para cada geração $g$, são tais que a equação (11A) se desdobra em

$$
\begin{array}{llll}
F_{a q}=0,0236 & R_{q}^{-0,8928,} \text { para } g=1 \\
F_{a q}=0,0343 & R_{q}^{-0,8928,} \text { para } g=2 \\
F_{a q}=0,0716 & R_{q}^{-0,8928,} \text { para } g=3 \\
F_{a q}=0,1901 & R_{q}^{-0,8928,} \text { para } g=4
\end{array}
$$

Este resultado demonstra uma Lei de potência para as forças viscosas $F_{a q}$, desenvolvidas em cada classe de tamanhos de obstáculos $q$, ao longo das gerações $g$ para abordagem simplificada. Em um segundo momento, foi construída uma abordagem aproximada, concernente aos dados obtidos diretamente dos resultados numéricos das simulações em CFD. Assim, analisando os gráficos $\ln F_{a q} \times \ln R_{q}$, mostrados na figura 7 (b), para os resultados obtidos nas simulações em CFD, referentes às gerações $g=2,3 e 4$, pode-se observar que o melhor ajuste para estes dados são retas, obtidas pelo Método dos Mínimos Quadrados, com coeficientes de determinação $r^{2} \geq 0,97$. Este valor indica que os ajustes conseguem explicar muito bem os valores observados. Portanto, tais resultados representam leis de escala, o que nos permitiram obter uma equação semelhante à anterior para as gerações de ordens $g=2,3 e 4$, , respectivamente.

$$
\begin{array}{lll}
F_{a q}=0,0489 & R_{q}^{-1,0172}, \text { para } & g=2 \\
F_{a q}=0,1019 & R_{q}^{-1,0600,} \text { para } g=3 \\
F_{a q}=0,2048 & R_{q}^{-0,9464}, \text { para } g=4
\end{array}
$$

Novamente, são leis de potências para as variáveis $F_{a q}$ e $R_{q}$. Neste caso, foram usadas as tensões de cisalhamento $\tau_{q x}$ determinadas pelas simulações para cada classe de tamanhos $q$ de uma determinada geração $g$. Fazendo uma analise preliminar dos resultados encontrados, podemos observar que, à medida que avançamos nas gerações, os coeficientes vão se aproximando, cada vez melhor, e que o expoente parece tender para o valor de $\left(1-D_{f f}\right)=-0,8928$, que é expoente da equação (11A) para a abordagem simplificada. Ou seja, é bastante provável que isso venha ocorrer.

A figura (10) mostra os resultados calculados pelas equações (11B) e (11C) para $F_{a q}$, segundo as duas abordagens adotadas, respectivamente. Os resultados mostraram-se razoáveis 
quando comparados entre si. A figura 10 (a) mostra o gráfico da distribuição das forças viscosas médias $F_{a q}$ desenvolvidas em cada classe de tamanhos $q$ para as gerações $\mathrm{G}_{2}, \mathrm{G}_{3}$ e $\mathrm{G}_{4}$, tanto para a abordagem simplificada, dada pelas equações (11B), linhas de cor preta, como pela abordagem aproximada, dada pelas equações (11C), linhas coloridas, respectivamente. Enquanto que a figura 10 (b) mostra o mesmo o comportamento, mas só que no gráfico $\ln F_{a q} \times \ln R_{q}$.
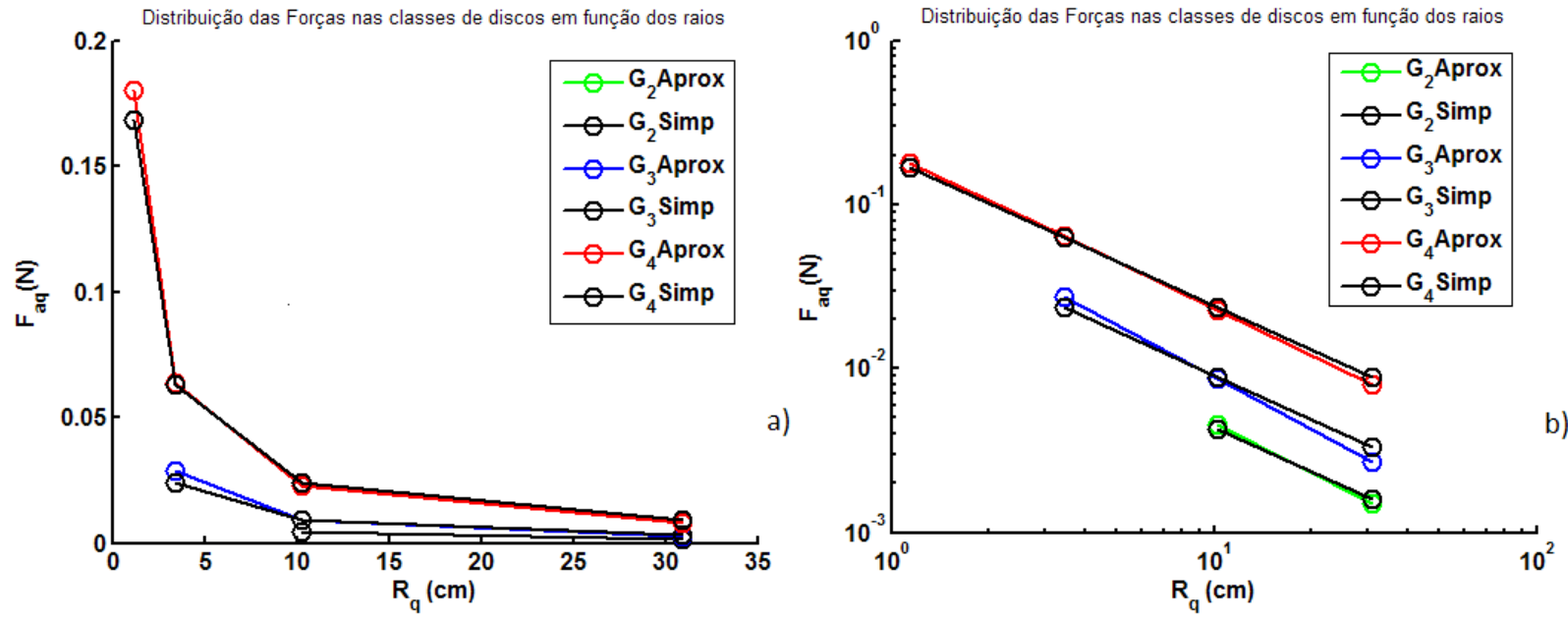

Figura 10: (a) Distribuição das forças viscosas médias $F_{a q}$ para as duas abordagens. (b) Mesmo comportamento no gráfico $\ln F_{a q} \times \ln R_{q}$.

Agora, fazendo uma análise mais compacta do fenômeno envolvido, podemos considerar a força de arrasto viscoso total $F_{a t}$ como sendo a soma de todas as forças $F_{a q}$ atuando em cada classe de tamanhos de obstáculos $q$, ou seja, $F_{a t}=F_{a 1}+F_{a 2}+\ldots+F_{a n}$. Desse modo, podemos, então, calcular a fração ou percentual correspondente a cada parcela das forças que atuam em cada classe de tamanhos em relação à força total. Ou seja, $F \%_{a q}=\frac{F_{a q}}{F_{a t}} \times 100$. Dessa forma, podemos ter uma ideia da significância de classe de tamanhos dos obstáculos no tocante à resistência viscosa oferecida ao fluxo de fluido no meio poroso. Isso simplifica o processo de análise dos resultados e mostra-se mais atrativo sob o ponto de vista prático. Para a abordagem simplificada e observando as equações (6) e (11A) e que os $C_{F q}$ são todos iguais, para uma determinada geração $g$, encontramos que

$$
F \%_{a q}=\frac{F_{a q}}{\sum_{i=1}^{g} F_{a i}}=\frac{C_{F q} R_{q}^{\left(1-D_{f f}\right)}}{C_{F 1} R_{1}^{\left(1-D_{f f}\right)} \ldots+C_{F q} R_{q}^{\left(1-D_{f f}\right)} \ldots+C_{F g} R_{g}^{\left(1-D_{f f}\right)}}=\frac{1}{\sum_{i=1}^{g} a^{\left(1-D_{f f}\right)(q-i)}}
$$

Este resultado demonstra uma equação simples, como função apenas do parâmetro geométrico $a$ e da dimensão fractal $D_{f f}$ dos modelos MPD para abordagem simplificada. A figura (11) mostra os resultados obtidos pela da equação (12) para $F \%_{a q}$ extrapolada até a sexta geração, ou seja, mostra o gráfico da distribuição das frações de forças viscosas médias $F \%_{a q}$ 
desenvolvidas em cada classe de tamanhos $q$ até a geração $\mathrm{G}_{6}$, para a abordagem simplificada. Esta mesma figura mostra também a envoltória construída pelas últimas classes de tamanhos para todas as gerações consideradas. Sendo que a mesma satura assintoticamente para um valor de $62,50 \%$, quando a geração $g$ tende para o infinito. Da mesma forma, para a penúltima e a antepenútilma classes de tamanhos, os correspondentes pontos de saturação são $23,44 \%$ e $8,79 \%$, respectivamente. Diante dos resultados obtidos, podemos observar que as três últimas classes de tamanhos fazem corresponder a uma parcela de $94,73 \%$ do total das forças de cisalhamentos ou viscosas envolvidas no fenômeno estudado. No intuito de generalizar e processar esta análise para classes de ordens superiores, observa-se há uma envoltória que satura para algum valor bem determinado, quando o número de gerações é suficientemente grande ou tende para o infinito. Ou seja, para um processo de fragmentação tendendo para o infinito há uma distribuição bem definida para os percentuais das forças para as classes de tamanhos $\mathrm{F}_{a q}$, caracterizado pelos pontos de saturação das envoltórias. Diante dos resultados obtidos nesta pesquisa, foi possível observar que as cinco últimas classes de tamanhos têm como ponto de saturação os seguintes valores: $62,50 \%, 23,44 \%, 8,78 \%, 3,30 \%$ e $1,24 \%$, respectivamente. Isto perfaz um total de $99,27 \%$ do total das forças de cisalhamento ou viscosas envolvidas no fenômeno. Por conseguinte, as últimas cinco classes de tamanhos absorvem, praticamente, toda energia de pressão desenvolvida para que o fluido venha a escoar através do meio poroso. Uma reta vertical traçada, neste gráfico, para qualquer geração $g$ identifica tanto as classes de tamanhos $q$, quanto às frações $F \%_{q q}$ correspondentes. É exatamente o caso exibido para a geração $\mathrm{G}_{4}$, identificam as classes $q$ e suas respectivas frações de forças viscosas, $F \%_{a q}$.

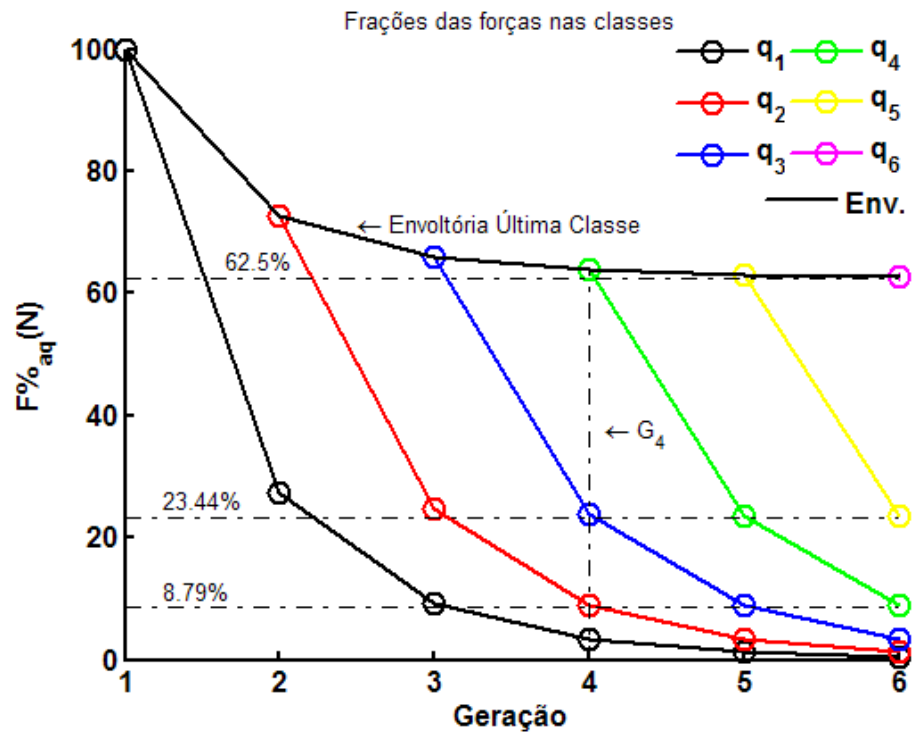

Figura 11: Distribuição das $F \%_{q q}$ até a geração $G_{6}$, para a abordagem simplificada; envoltória ; identificação, para a geração $g=4$.

Para a abordagem aproximada, observando as equações (6) e (11A), os coeficientes $C_{F q}$ são distintos, dependendo da classe $q$. Agora, se admitirmos que a tensão de cisalhamento $\tau_{q x}$ se relaciona com os tamanhos dos discos $R_{q}$ segundo uma lei de potência, ou seja,

$$
\tau_{q \times}=C_{\tau} R_{q}^{(\beta)} \text {, então, } C_{F q}=\frac{1}{50} \pi C_{\tau} R_{q}^{(\beta)} C_{R}
$$


Por conseguinte, a força de cisalhamento $F_{a q}$ agora será dada por

$$
F_{a q}=C_{F q} R_{q}^{\left(1-D_{f f}\right)}=\frac{C_{\tau} C_{R}}{50} \pi R_{q}^{(\beta)} R_{q}^{\left(1-D_{f f}\right)}=C_{\gamma} R_{q}^{\left(\beta+1-D_{f f}\right)}=C_{\gamma} R_{q}^{\gamma}
$$

onde $C_{\gamma}=C_{\tau} C_{R} \pi / 50$ e $\gamma=\left(\beta+1-D_{f f}\right)$. O que é equivalente a dizer que existe um lei de escala entre $F_{a q}$ e $R_{q}$. Isto já foi constado numericamente pelas equações (11C). O que reforça a nossa hipótese sobre $\tau_{q x}$. Neste caso, os valores para $C_{\gamma}$ e $\gamma$ são iguais para cada geração, então a equação para as frações $F \%_{a q}$ é dada por

$$
F \%_{a q}=\frac{F_{a q}}{\sum_{i=1}^{g} F_{a i}}=\frac{C_{\gamma} R_{q}^{\gamma}}{C_{\gamma} R_{1}^{\gamma} \ldots+C_{\gamma} R_{q}^{\gamma} \ldots+C_{\gamma} R_{g}^{\gamma}}=\frac{1}{\sum_{i=1}^{g} a^{\left(\beta+1-D_{f f}\right)(q-i)}}
$$

Este resultado demonstra uma equação não tão simples como função do parâmetro geométrico $a$, fator de escala; da dimensão fractal $D_{f f}$ dos modelos MPD; e do expoente $\beta$, que depende de cada geração $g$ considerada, para abordagem aproximada. Os valores para $\gamma=\left(\beta+1-D_{f f}\right)$ são os expoentes das equações (11C), ou seja, [-1,0172 -1,0600 -0,9464] para as gerações de ordens $g=2,3$ e 4 , respectivamente. Os resultados fornecidos pelas equações (12) e (15) são tecnicamente semelhantes sob o ponto de vista prático; ou seja, aproximam-se dos resultados obtidos diretamente das simulações. Afirmamos ainda que, quando a ordem da geração tende para o infinito, os resultados parecem aproximar-se mais ainda; isto é $\beta$ tende-se a zero. A tabela 2 mostra os resultados, para as frações das forças viscosas, obtidos diretamente das simulações, tanto pela abordagem simplificada, como pela aproximada.

Por outro lado, a tabela 2, logo a seguir, apresenta os valores das tensões de cisalhamento $\tau_{q x}$ das forças de arrasto viscoso $F_{a q}$. Apresenta também as frações $F \%_{a q}$ em relação à força total desenvolvida no meio poroso. Tudo isto, para cada classe de tamanhos $q$ correspondentes às gerações $g=1(2,3 e 4)$. Resultados obtidos diretamente das simulações em CFD. Nas duas últimas colunas, resultados obtidos pelas abordagens aproximada, dada pela equação (15), e simplificada, dada pela equação (12), respectivamente Mostra também que os resultados estão de acordo com as conclusões tiradas até agora, ou seja, as classes de menores tamanhos é que detêm os maiores percentuais de forças de cisalhamento. Isto significa que o processo de fragmentação das partículas, caracterizado pela dimensão fractal do modelo MPD, interfere significantemente na distribuição das forças de cisalhamento em relação aos tamanhos das partículas. Mais precisamente, num processo infinito, a poeira formada pelas partículas menores é responsável por uma parcela considerável de toda a força viscosa desenvolvida no sistema. Quando a ordem das gerações tende para o infinito, as três últimas classes de tamanhos absorvem praticamente mais de $90 \%$ do total das forças viscosas desenvolvidas no sistema; enquanto que, as cinco últimas classes de tamanhos absorvem praticamente mais de $99 \%$. Ver figura 11. Isto é um forte indicativo de que as classes de tamanhos menores (a poeira) absorvem praticamente toda energia de pressão necessária para um possível fluxo de fluido no meio poroso aqui estudado.

Tabela 2: Apresenta os valores das tensões de cisalhamento $\tau_{q x}$ das forças de arrasto viscoso $F_{a q}$. A presenta também $F \%_{a q}$ em relação à força total desenvolvida no meio poroso. 


\begin{tabular}{|c|c|c|c|c|c|}
\hline $\begin{array}{c}\text { Classe } \\
\qquad q\end{array}$ & $\begin{array}{c}\text { Tensão } \\
\text { cisalhamento } \\
\text { (CFD) } \\
\tau_{\mathrm{qx}}\left(\mathrm{N} / \mathrm{m}^{2}\right)\end{array}$ & $\begin{array}{c}\text { Força } \\
\text { viscosa } \\
\text { (CFD) } \\
\mathrm{F}_{\mathrm{qx}}(\mathrm{N})\end{array}$ & $\begin{array}{c}\text { Fração força } \\
\text { viscosa } \\
\text { (CFD) } \\
\text { F\% }{ }_{\text {aq }}(\%)\end{array}$ & $\begin{array}{c}\text { Fração força } \\
\text { viscosa } \\
\text { (aproximada) } \\
\text { F\% }{ }_{a q}(\%)\end{array}$ & $\begin{array}{c}\text { Fração força } \\
\text { viscosa } \\
\text { (aproximada) } \\
\text { F\% }{ }_{\text {aq }}(\%)\end{array}$ \\
\hline \multicolumn{6}{|c|}{ Geração 1} \\
\hline 1 & 0,0006 & 0,0011 & 100,00 & -------- & -------- \\
\hline \multicolumn{6}{|c|}{ Geração 2} \\
\hline 1 & 0,0008 & 0,0015 & 24,65 & 24,64 & 27,27 \\
\hline 2 & 0,0009 & 0,0045 & 75,35 & 75,35 & 72,72 \\
\hline \multicolumn{6}{|c|}{ Geração 3} \\
\hline 1 & 0,0015 & 0,0029 & 7,29 & 6,91 & 9,28 \\
\hline 2 & 0,0015 & 0,0077 & 19,21 & 22,14 & 24,74 \\
\hline 3 & 0,0022 & 0,0296 & 73,50 & 70,95 & 65,98 \\
\hline \multicolumn{6}{|c|}{ Geração 4} \\
\hline 1 & 0,0045 & 0,0087 & 3,07 & 2,90 & 3,36 \\
\hline 2 & 0,0039 & 0,0204 & 7,2 & 8,21 & 8,97 \\
\hline 3 & 0,0044 & 0,0602 & 21,28 & 23,22 & 23,91 \\
\hline 4 & 0,0055 & 0,1936 & 68,45 & 65,67 & 63,76 \\
\hline
\end{tabular}

\section{CONCLUSÕES}

Resumindo:- Neste trabalho foram analisadas as propriedades do fluxo bidimensional de um fluido, particularmente o óleo em um meio poroso heterogêneo, formado por um conjunto de discos de tamanhos diferentes, dispostos aleatoriamente em um canal retangular. A distribuição dos tamanhos destes discos segue uma lei de potência, em que o expoente define a dimensão fractal do sistema. Apesar da natureza não-linear da dinâmica de fluidos viscosos e da complexa geometria do espaço poroso intersticial, foi possível verificar que, devido ao processo de fragmentação sucessivo do sistema, caracterizado por uma distribuição fractal para os tamanhos dos obstáculos, cuja medida é sua dimensão fractal de fracionamento, ocorre um aumento progressivo da área de contato fluido-sólido. Como consequência, haverá uma alteração significativa na estrutura do fluxo de fluido, interferindo diretamente na configuração das distribuições das tensões de cisalhamento desenvolvidas nas superfícies das partículas sólidas do meio poroso. Isto acarreta um aumento na medida do arrasto de atrito ou viscoso desenvolvido no meio. Com base nos resultados numéricos, obtidos de simulações em CFD, foi possível determinar relações de escala, leis de potência, envolvendo relevantes parâmetros que caracterizam o fenômeno físico envolvido no problema em questão. Ou seja, permitiu-se encontrar relações algébricas, leis de potência, entre a força de arrasto viscoso, ou de atrito, e os tamanhos dos obstáculos do meio para o modelo MPD, considerado nesta pesquisa. Foi possível, também, fazer inferências sobre as distribuições das frações dessa força com relação às classes de tamanhos dos obstáculos, chegando à conclusão de que as partículas menores detêm cerca de $62,50 \%$ do total das forças viscosas desenvolvidas no sistema, mais precisamente nas superfícies dos obstáculos, e que as três últimas classes de tamanhos menores, detêm 94,73\%. Ainda, que as cinco últimas classes de tamanhos menores, detêm 99,27\%. Ou seja, num processo de fragmentação tendendo para o infinito, como o estudado nesta pesquisa, a poeira formada pelas partículas menores consome praticamente toda energia de pressão que é direcionada para as tensões de cisalhamento desenvolvidas nas superfícies dos obstáculos que compõem o meio poroso. Neste trabalho só foi possível realizar simulações numéricas para as amostras até a 
quarta geração, devido às limitações de ordem computatacional. Isto restringe o estudo a meios porosos com valores relativamente elevados para a porosidade. Apesar disso, nesta pesquisa, a metodologia empregada mostrou-se adequada às simulações em meios porosos simplificados por modelos geométricos fractais, v. g. MPD, cuja construção tomou como base o clássico Tapete de Sierpinski.

\section{AGRADECIMENTOS}

Os autores agradecem ao IFRN, CNPq, FINEP, CTPETRO, FAPERN, CAPES e da Rede Cooperativa de Pesquisa em Geofísica de Exploração pelo apoio financeiro a este trabalho.

\section{REFERÊNCIAS BIBLIOGRÁFICAS}

1. F. A. L. DULLIEN Fluid Transport and Pore Structure. Academic, New York, 1979.

2. J. BEAR. Dynamics of Fluids in Porous Media. Dover, New York, 1988.

3. M. SAHIMI. Flow and Transport in Porous Media and Fractured Rock. VCH, Boston, 1995.

4. K. AZIZ. Petroleum Reservoir Simulation. Applied Science Publishers LTD, London, 1979.

5. J. S. ANDRADE et al. Percolation disorder in viscous and nonviscous flow through Porous Media. PHYSICAL REVIEW E, Number 6, Vol. 51, Received in 30 November 1994. June 1995.

6. J. S. ANDRADE et al. Fluid Flow through Porous Media: The Role of Stagnant Zones. Physical Review Letters, Number 20, Vol. 79, 7 May 1997.

7. H. H. MACEDO et al. Turbulent effects on fluid flow through disordered porous media, Physica A, 299 (2001). 371377.

8. BARROCA NETO, A. Simulação de fluxo de fluido em meios porosos desordenados. Uma análise de efeito de escala na estimativa da permeabilidade e do coeficiente de arrasto. Tese de Doutorado. Programa de Pós-Graduação em Ciência e Engenharia de Petróleo. UFRN. Natal-RN, Brasil, 2012.

9. ÇENGEL, Y. A. \& CIMBALA, J. M. Mecânica dos Fluidos - Fundamentos e aplicação. 1a ed. Editora MC Graw Hill, São Paulo-SP, Brasil, 2007.

10. FOX, ROBERT W. Introduction to Fluid Mechanics. Sixth Edition, JOHN WILEY \& SONS, INC., Copyrighted Material, Hoboken, NJ, 2006.

11. APIANO F. MORAIS et al. Non-Newtonian Fluid Flow through Three-Dimensional Disordered Porous Media, Three-Dimensional Disordered Porous Media. Phys. Rev. PRL 103, 194502, 2009.

12. J. S. ANDRADE et al. The distribution of local Fluxes in Porous Media. , rXiv:physics/0511085 v1, 09 Nov, 2005.

13. RAFAEL S. OLIVEIRA et al. Fluid flow through Apollonian packings. Physical Review E 81, 047302, 2010.

14. P. R. KING et al. Predicting oil recovery using percolation theory. Petroleum Geoscience, EAGE, Vol. 7, No Supp, May 2001 pp. 105 - 107.

15. FLUENT user manual. FLUENT Inc., Lebanon, New Hampshire, USA. FLUENT is a CFD package. 
16. S. V. PATANKAR. Numerical Heat Transfer and Fluid Flow. Hemisphere, Washington DC, 1980.

17. GAMBIT user manual. FLUENT Inc., Lebanon, New Hampshire, USA. GAMBIT is a package to generation mesh models for CFD analysis.

18. GILAT, A. MATLAB - com aplicação em engenharia, 1a ed., Editora Interciência Ltda, Rio de Janeiro, PETROBRAS, Brasil, p. 808, 2006.

19. MANDELBROT, BENOIT B. The fractal geometry of nature. W.H. Freeman, New York, 1983.

20. FISHER, YUVAL. Fractal Image Compression, Theory and Application. Springer-Verlag, New York, Inc, 1995.

21. H. EUGENE STANLEY AND JOSÉ S. ANDRADE JR. Physics of the cigarette filter: fluid flow through structures with randomly-placed obstacles. Physica A 295 (2001) 1730. 